
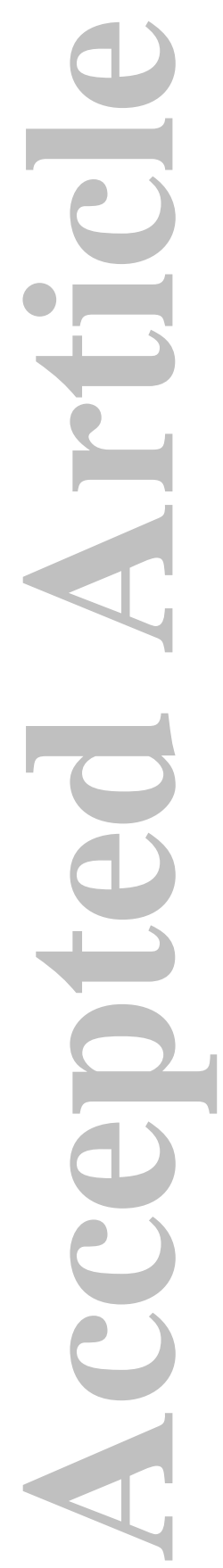

This is the author manuscript accepted for publication and has undergone full peer review but has not been through the copyediting, typesetting, pagination and proofreading process, which may lead to differences between this version and the Version record. Please cite this article as doi:10.1111/ psyp.13040.

This article is protected by copyright. All rights reserved. 
ERN AND EF 1

Running Head: ERN AND EF

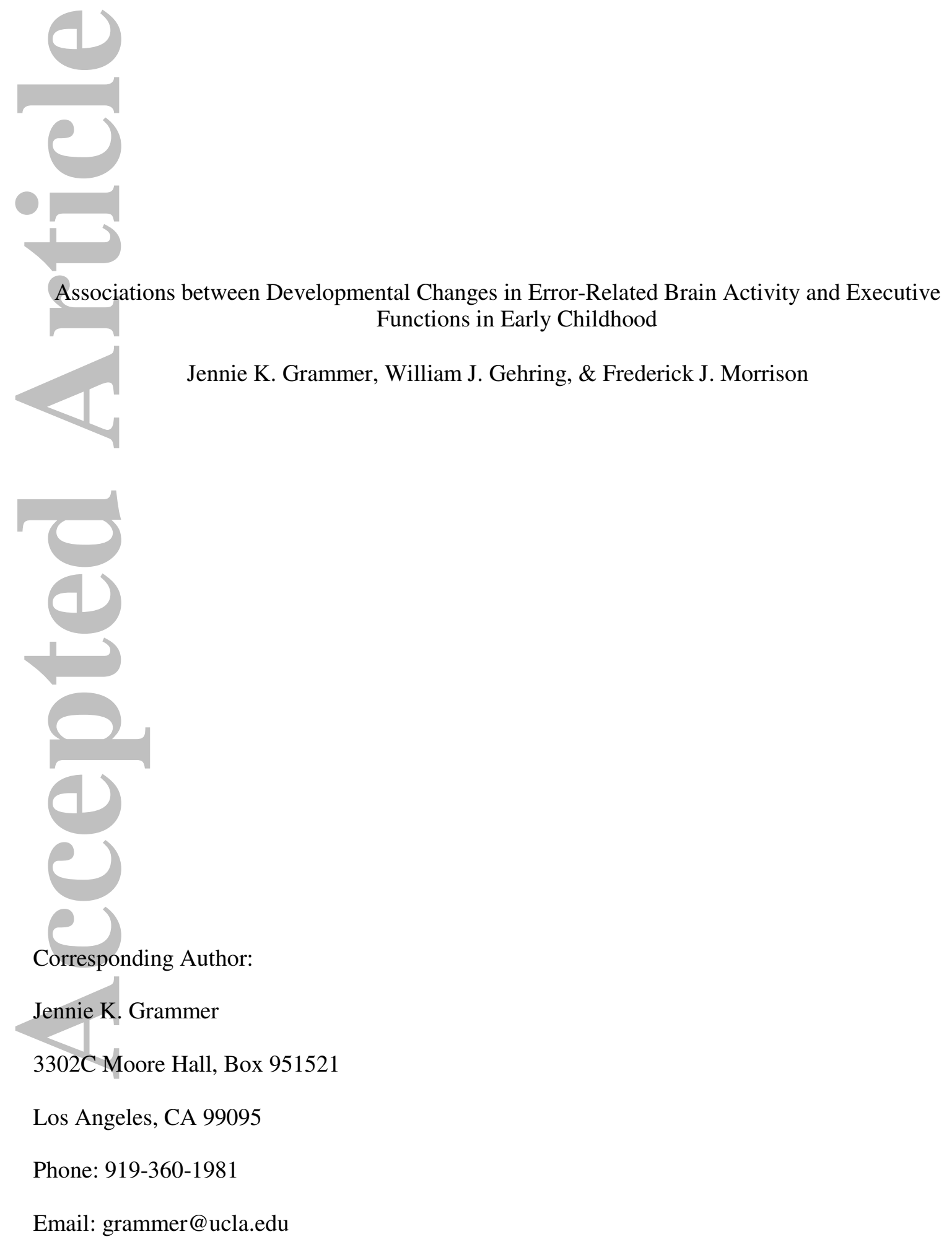

Psychophysiology

This article is protected by copyright. All rights reserved. 


\begin{abstract}
Behavioral evidence indicates that skills associated with children's cognitive control (e.g., response inhibition and attentional control) undergo rapid development during early childhood.

A particularly important time is the transition to elementary school. Yet, at present relatively little is known about developmental changes in the brain processes linked to cognitive control during this period, including those associated with error monitoring, including the error-related negativity (ERN) and the error positivity (Pe). Moreover, understanding how ERP correlates of cognitive control relate to behavioral measures of these skills over time is also limited. In the present study, repeated assessments of 4-6 yr. old children's $(\mathrm{N}=49$, mean age $=5$ years 10 months) performance on a Go/No-Go task, were collected to examine developmental changes in error processing and response inhibition across 6 months. Data revealed the presence of both the ERN and Pe at each timepoint, but also showed individual differences in the test-retest associations for each component. Behavioral changes in response inhibition on the Go/No-go task and a standardized measure of attentional control were associated with changes in electrophysiological measures of error processing. Additional analyses comparing children of the same age who had completed the Go/No-go task once to those who participated longitudinally revealed that with repeated assessments, children exhibited behavioral changes in performance that could be attributed to both development and to the effects of practice, such as strategic accommodation.
\end{abstract}

Keywords: error-related negativity, cognitive control, school-aged children, error positivity 
ERN AND EF 3

\section{Associations between Developmental Changes in Error-Related Brain Activity and Executive Functions in Early Childhood}

With increased attention to the role of Executive Functions (EF) for children's early

school success, development of these skills - including response inhibition and attention control -

has received increasing attention from researchers in disciplines ranging from developmental psychology to cognitive neuroscience (Anderson, 2002; Duckworth \& Seligman, 2006; Luciana, 2003; Zelazo, Craik, \& Booth, 2004). Outside of the developmental literature, some components of EF are known as aspects of cognitive control. Although the concepts of EF in the developmental literature and cognitive control in the cognitive literature are not identical, they share common processes, and discovering how they correspond is a major objective in linking the two (Morrison \& Grammer, 2012).

In part due to the importance of these skills for school readiness, there has been a proliferation of developmental researchers examining the neural correlates cognitive control processes using event-related potentials in young children (Downes, Bathelt, \& De Haan, 2017). To date, however, the majority of this research has been cross-sectional, providing limited insight into developmental changes within children over time (e.g., Clawson, Clayson, Keith, Catron, \& Larson, 2017; Davies, Segalowitz, \& Gavin, 2004; Ladouceur, Dahl, Birmaher, Axelson, \& Ryan, 2006; Santesso \& Segalowitz, 2008; Tamnes, Walhovd, Torstveit, Sells, \& Fjell, 2013). Indeed, although wealth of investigations provide support for age-related differences and longitudinal changes in children's EF across the early elementary school years as assessed behaviorally, much less is known about developmental changes in electrophysiological correlates of these abilities there are few reports on developmental changes in ERP components involving longitudinal data collected with young children (exceptions include DuPuis et al., 2015; Meyer, Bress, \& Proudfit, 2014) .Longitudinal data from children provide a richer set of constraints on theories of cognitive control, by enabling us to show how variability in behavior over time- - within an individualderives from developmental changes in his or her brain. 
ERN AND EF 4

Here, capitalizing on the benefits of longitudinal designs for understanding the development neural correlates of cognitive control processes, we show how taking a transdisciplinary approach linking the developmental and cognitive perspectives can shed light on the fundamental mechanisms of interest in the study of cognition and development. Specifically, in this investigation, behavioral and electrophysiological correlates of response inhibition were assessed across two time points using a child-friendly Go/No-go task. Testing kindergarten and first grade children in the fall and spring of the academic year, it was possible to examine how growth in response inhibition was related to changes in other aspects of cognitive control. Thus, focusing on the behavioral and ERP correlates of cognitive control, and a standardized behavioral measure of attentional control, we examined developmental changes in 5-7 year old children's brain and behavior across one academic year to address the following questions: 1) to what extent are behavioral indices of EF related to those assessed electrophysiologically? and 2) what are the relations between ERP indices of cognitive control and growth of related skills outside the laboratory?

\subsection{The Development of Cognitive Control Processes in Early Childhood}

Our study is guided by the framework assumed by many approaches to cognitive control (e.g., Botvinick et al., 2001; Yeung eta 1., 2004; Holroyd and Coles 2002; Coles et al., 2001;

Alexander \& Brown, 2010; see Gehring et al., 2012 for a review). The general framework is that computations exist that detect breakdowns in performance and signal the need for cognitive control, and control processes act upon such signals to optimize performance and prevent further breakdowns by adjusting attention, motor control, reward processing, and other computations so that breakdowns are less likely.We focus here on three integral parts of this cycle: response inhibition processes that are needed to prevent errors from occurring in situations where prepotent responses are likely to occur, error monitoring processes that detect when response inhibition other processes have failed, causing an error, and attention control processes that govern the 
ERN AND EF 5

allocation of attention and the access of attended information to the motor system. This general framework is common to the models listed above, although many details differ between the models in ways that exceed that precision with which constructs are specified in developmental studies of EF and are therefore beyond the scope of our study.

is not as simple as measuring them in the same study and correlating them across time. One challenge in linking constructs derived from the literatures on cognitive control (principally from cognitive neuroscience and computational modeling) with those from the literature on executive function (from psychometric testing within developmental psychology) is that the constructs bear some similarity and even overlap in some cases, but they are not identical, nor are they always specific to the construct they purport to measure. A measure of attentional control in cognitive neuroscience (e.g., the conflict adaptation effect; Botvinick et al., 2001) doesn't map to the underlying computations as the measure of attentional control in psychometric tests of EF (e.g., the Woodcock Johnson Tests of Cognitive Skills, (Woodcock \& Mather, 2000). A second-bysecond breakdown of the various attention and response-related processes engaged when a child performs the Woodcock-Johnson would almost certainly include the kind of attention control seen in the conflict-monitoring model, but there are numerous other processes that result in a child's score, and some of them are likely not attention-related at all. Similarly, although speed and accuracy in a Go/No-go task are often accepted as a measure of a child's response inhibition ability (e.g., Willoughby et al., 2010), it is certainly the case that other processes govern a child's score. Thus while psychometric and experimental tests of EF constructs are sensitive to the constructs they purport to measure, they are sensitive to other variables as well.

The difficulty of linking constructs across domains is even clearer considering the central focus of this research, error monitoring. Theories of cognitive control (such as the conflictmonitoring theory; Botvinick et al., 2001; Yeung et al., 2004) describe processes that detect 
breakdowns in performance either via errors or the presence of response conflict. The detection of errors or response conflict signals the need for control, leading to adjustments (e.g., in the focus of attention) to prevent future breakdowns. Hence error (and conflict) monitoring instigates the cycle. Despite the centrality of this construct in computational modeling and cognitive neuroscience, studies of EF in developmental psychology do not place as much importance on error-monitoring, and there are no EF tasks - experimental or psychometric-that yield behavioral measures suitable for tracking the development of error monitoring ability.

Hence, the focus of the present study is on the development of error monitoring and its relationship to two constructs traditionally assessed in developmental studies of EF: attention control and response inhibition. If we were fortunate enough to have a pure measure of error monitoring, a pure measure of an attention control process, and a pure measure of a response inhibition process, we would have straightforward predictions: individual variation in the error monitoring process should be related to individual variation in attention control and response inhibition, if indeed all reflect the activity of an integrated EF system. However, we do not have such measures and thus our focus here is on the measures we do have: electrophysiological measures of error monitoring and behavioral measures of attention control and response inhibition. Thus, failures to find that one measure is not related to another do not uniquely disconfirm the notion that that development of one process is predictive of the development of another. Instead, such a failure could indicate shortcomings in the measures of those constructs that fail to reveal links that do exist and would be evident if we had better measures. In our view, this is an appropriate level at which to begin empirical work attempting to link the domains of inquiry regarding cognitive control and $\mathrm{EF}$, and future work can build on the work we report here by further developing more precise measures and computational models of childhood EF.

\subsection{Electrophysiological Indices of Error Monitoring on Cognitive Control Tasks}

Psychophysiological studies of children's cognitive control processes have focused on changes in ERP components that reflect a network of structures involved in detecting response 
ERN AND EF 7

conflict and in attentional control, including the anterior cingulate cortex (ACC) and lateral prefrontal cortex. The ACC has been implicated in cognitive control functions that enable the brain to adapt behavior to changing task demands and environmental circumstances (Botvinick et al., 2001; Chiew \& Braver, 2017) .

There are limited longitudinal data regarding the development of the ACC; however, evidence from cross-sectional studies conducted in adolescence and later childhood provides some evidence linking changes in the ACC with concurrent age-related growth observed in performance monitoring (Tamnes et al., 2013). There has also been increasing attention to two ERP components associated with cognitive control functions: the Error-Related Negativity (ERN, or $\mathrm{Ne}$ ) and the Error Positivity (Pe), which are elicited when individuals err in speeded response tasks involving response conflict. The ERN is a response-locked negative deflection usually seen at midline frontocentral scalp locations that peaks 50-100 ms following an erroneous response in speeded choice reaction time (RT) tasks (Falkenstein, Hohnsbein, Hoormann, \& Blanke, 1991; Gehring, Goss, Coles, Meyer, \& Donchin, 1993). The Correct-Response Negativity (CRN), can also been identified on correct trials at the same latency as the ERN ( see Gehring, Liu, Orr, \& Carp, 2012 for a review of both components). Because commission of an error provides an indication that cognitive control is needed, theories of the ERN have tended to argue for its role in detecting the need for or in implementing cognitive control. Most theories relate the ERN to the detection of an event signaling a breakdown in performance: erroneous behavior (Coles et al. 2001), response conflict (Yeung et al., 2004), "worse than expected" reinforcement events (Holroyd et al., 2002), or unexpected response outcomes (Alexander \& Brown, 2010)

The presence of the ERN is often accompanied by the Pe, a positivity reaching maximum amplitude between 200-400 ms after the commission of an error that usually follows the ERN (Overbeek et al., 2005). Although the functional significance of the Pe is still unclear, the Pe has been associated more frequently than the ERN with conscious awareness of having made an error (Nieuwnhuis, Ridderinkhof, Blom, Band, \& Kok, 2001). Consistent with this, the Pe is thought 
ERN AND EF 8

to capture affective responses to committing an error, awareness of having made an error, or processing related to adapting response strategies after a mistake has been made (Falkenstein, 2004; Overbeek et al. 2005). In addition, the amplitude of the Pe has been linked to academic achievement (Kim et al., 2016) and motivational processes (Kim, Marulis, Grammer, Morrison, \& Gehring, 2017) in young children.

\subsection{Developmental Changes in the ERN and Pe}

Recent findings have revealed that although age-related differences in the ERN and behavioral measures (e.g., RT) on Flanker and Go/No-Go tasks are not always robust in young children, intraindividual variability in behavioral performance is related to the ERP measures (Richardson, Anderson, Reid, \& Fox, 2011; Torpey, Hajcak, Kim, Kujawa, \& Klein, 2012). In addition, although little is known about the stability of ERP components across repeated assessments of tasks used frequently with young children, one report in which children were assessed using a Flanker task to investigate the ERN over 2 weeks (Davies \& Gavin, 2009) indicates that test-retest correlations in children are relatively low, whereas similar assessments of adults across a few weeks and even two years reveal greater stability (Olvet \& Hajcak, 2009).

In contrast to the growing literature on age-related changes in the ERN, less is known about the development of the Pe. Some investigations with children in middle childhood and adolescence have found no evidence of differences in the Pe as a function of age (Davies et al., 2004; Hogan, Vargha-Khadem, Kirkham, \& Baldeweg, 2005; Santesso, Segalowitz, \& Schmidt, 2006; Wiersema, van der Meere, \& Roeyers, 2007), whereas age-related differences have been observed in studies of younger children (Grammer, Carrasco, Gehring, \& Morrison, 2014).

\subsection{Linking Error Monitoring with Cognitive Control}

There are reasons to think that error monitoring and cognitive control processes are important to consider across the transition in to elementary school. Indeed, it seems likely that processes underlying ERPs associated with error monitoring are important for the cognitive 
ERN AND EF 9

control skills children employ in the classroom (Roebers, 2017). Monitoring one's performance becomes an increasingly important aspect of children's repertoire of regulatory skills as they progress through elementary school. As children engage in academic tasks and monitor their performance, they must employ metacognition (e.g., Carr, 2010; Roebers, Krebs, \& Roderer, 2014), including skills for metacognitive monitoring (e.g., confidence judgments) and control processes (e.g., detecting and correcting errors) (e.g., Schneider, Schlagmuller, \& Vise, 1998).

Developmental research on performance monitoring shows that young children tend to be inaccurate in estimating their abilities, often overestimating their skill. Although this bias towards overconfidence remains a prominent feature of metacognitive reports in early childhood, there is an increase in children's performance monitoring accuracy from early to late elementary school (Desoete \& Roeyers, 2006). Just as children's capacity for engaging in error monitoring is thought to be changing across this period of time, so too is the salience of external feedback relative to internal feedback. With age, the need for external reinforcement (e.g., from teachers and parents) is thought to decrease, and children become increasingly efficient at monitoring their own errors and using this information to inform future performance.

\subsection{Relating ERP Markers of Error Monitoring to Behavioral Development: The Current}

\section{Investigation}

Given the importance of performance monitoring for the adjustment of behavior, here we explore whether developmental changes in children's ability to engage in efficient error monitoring, as indexed by ERP correlates of these processes, could give insight into individual differences in the development of cognitive control. Indeed, as children's ability to detect the need for cognitive control processes, so too could their ability to engage in specific cognitive control processes. To examine this possibility, and to address basic questions regarding developmental changes in error monitoring, employing longitudinal data involving brain and behavioral correlates of cognitive control, the goals of this investigation were to: 1) test the 
associations between ERP correlates of error monitoring across a school year, 2) examine associations between ERP and behavioral measures over time within a response inhibition task, and 3) explore the extent to which changes in the ERN and Pe are related to changes in behavioral indices of response inhibition (Go/No-go) and attentional control (Pair Cancellation). In addition, making use of sample of children assessed only one time, we examine the role of maturation relative to repeated experience with a task in children's behavioral performance.

(

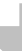

\subsection{Participants}

In total, 49 children ( 24 girls, 25 boys) contributed ERP data for these analyses

examining changes in performance longitudinally across two time points. On average these children were 5 years, 8 months old $(\mathrm{SD}=.58$, range $=4.92-6.92$ months $)$ at the first assessment and 6 years, 3 months $(\mathrm{SD}=.58$, range $=5.33-7.42$ months when assessed at the end of the school year. All children were recruited from Kindergarten and First Grade classrooms in two elementary schools. The diversity of the sample reflected the Midwestern suburban area from which the participants were drawn, with $75 \%$ of the families describing their ethnicity as Caucasian, $12 \%$ as African American, 5\% as Hispanic, 5\% as Asian, and 3\% as being of mixed ethnicity. An additional 4 children participated, but ERP data were not collected. Two of these children opted not to participate in the ERP assessment at the fall time point, one experienced data loss due to a technical issue with equipment, and one had an assessment terminated after the first block of the task due to an unannounced tornado drill.

In addition to this longitudinal sample, a second cohort of children was assessed, here referred to as the Control Group, at one time point only $(n=33)$. These children were recruited from the same schools as the children in the longitudinal study and were similar in age and grade (Mean age at assessment $=6$ years, 5 months; 14 girls, 19 boys). However, while the longitudinal group participated in the assessments in the fall and spring of the school year, these children were 
assessed only once in the spring. Thus, the two groups of children are matched on age and experience in school, but vary in the extent to which they were exposed to testing.

\subsection{Procedure}

Children in the longitudinal sample participated in behavioral and electrophysiological (EEG) assessments at two time points, once in the fall and once in the spring of the school year. During each EEG assessment, children completed a Go/No-go task. Behavioral assessments of children's response inhibition control were also conducted in the fall and spring of each year in a separate session. EEG assessments were separated by 181.26 days on average (SD = 11.28).

Children in the control group were assessed only in the spring using the same battery of

measures. Testing with this group was conducted during the same time (spring) in the school year as the second test of the longitudinal group, although in a different calendar year.

\subsection{Measures}

\subsubsection{Response Inhibition: The Go/No-Go Task}

Participants performed a child-friendly Go/No-go task called the Zoo Game (Grammer et al., 2014), in which children were told that they were playing a game in which their goal was to help a zookeeper put animals back in their cages. They were then informed that three of the animals, orangutans, were helping the zookeeper. In this way, children were asked to press a button as quickly as they can every time they saw an animal (Go Trials) but to inhibit their response each time they saw an orangutan (No-Go trials).

The task began with a brief practice block consisting of 12 trials, 9 with zoo animals and 3 with orangutans. The children then completed 8 blocks of the task, each with 40 trials (each including 10 images of the orangutans and 30 novel zoo animal pictures), for a total of 320 trials. Each animal image was preceded by a fixation cross displayed for a randomized interval ranging between 200-300 ms. The stimuli were presented for $750 \mathrm{~ms}$, followed by a blank screen for 500 ms. Responses could be made while the stimulus was on the screen or at any point during following 500ms. Each block consisted of novel sets of animal photographs, and each set was 
balanced with respect color, animal type, and size. RT and accuracy were also recorded. ERP measures consisted of the amplitude and scalp distribution of the ERN and Pe elicited when children respond incorrectly in the task.

\subsubsection{Behavioral Measures}

Behavioral measures included the number and percentage of error and correct trials for each subject as well as children's RTs. Children could be correct on both Go trials by correctly responding to any animal that was not an orangutan and on No-Go trials by correctly inhibiting a response when seeing an orangutan. Errors were evaluated only for No-go trials, where children committed errors of commission by responding.

Participants with fewer than 6 error trials overall were not included in ERP analyses $(\mathrm{n}=$ 2). For two additional children, technical errors resulted in 1 or 2 missing blocks of data. Because both of these children maintained the necessary number of error trials to be evaluated in the analyses, their ERP data were retained and the percentage of the total accurate and error trials are used in all analyses. No differences with respect to age, gender, or grade were found between children who contributed data and those with an insufficient number of errors in the sample.

Average RTs on error and correct trials were calculated separately. Trials with RTs that occurred after $1250 \mathrm{~ms}$ were not included.

\subsubsection{ERP data collection and analyses}

ERP assessments were conducted in conference rooms in children's elementary schools by two experimenters. Each participant was seated directly in front of the computer monitor and told to place equal emphasis on speed and accuracy in responding. Following a practice block of 12 trials, participants completed 8 blocks of 40 trials. Performance feedback was provided after every block to yield error rates of approximately $10 \%$, ensuring an adequate number of trials for stable error-related waveforms. To increase compliance and reduce fidgeting during ERP recording, children were given brief breaks in between each block. Feedback was also provided, in the form of a "Zoo Map" allowing children to monitor their progress through the task. 
ERN AND EF 13

\subsubsection{Electrophysiological Recording, Data Reduction, and Analysis}

The EEG was recorded from DC-104 Hz with $32 \mathrm{Ag} / \mathrm{AgCl}$ scalp electrodes, two mastoid electrodes, and two vertical and two horizontal electro-oculogram electrodes, using the BioSemi ActiveTwo system. Data were recorded referenced to a ground formed from a common mode sense active electrode and driven right leg passive electrode (see http://www.biosemi.com/faq/cms\&drl.htm). Data were digitized at $512 \mathrm{~Hz}$. Following recording the data were resampled at $256 \mathrm{~Hz}$. Prior to eye movement correction, EEG data were screened using automated algorithms that rejected individual sweeps in which (a) the absolute voltage range for any individual electrode exceeded $500 \mu \mathrm{V}$ (the range was kept somewhat large to allow correctable EOG artifacts to remain), (b) a change greater than $50 \mu \mathrm{V}$ was measured from one datapoint to the next, or (c) the data deviated by more than +25 or $-100 \mathrm{~dB}$ in the $20-40 \mathrm{~Hz}$ frequency window (for detecting muscle artifacts). Data were also screened by visual inspection. Ocular movement artifacts were then corrected using the algorithm described by Gratton, Coles, and Donchin (1983). Waveforms shown in figures were filtered with a nine-point Chebyshev II low-pass, zero-phase-shift digital filter (Matlab R2010a; Mathworks, Natick, MA), with a halfamplitude cutoff at approximately $24 \mathrm{~Hz}$.

Following these data processing methods, ERP data for 45 children were included in the final analyses. Data from 2 children were missing at one time point due to technical issues, and 2 additional children had data that were too noisy to be retained post-processing. These 4 children were removed from subsequent ERP analyses. All remaining children had complete data for both fall and spring time points.

\subsubsection{ERP Measures}

The ERN, CRN, and Pe were quantified using mean amplitude measures at midline electrode sites ( $\mathrm{FCz}, \mathrm{Cz}$, and $\mathrm{Pz}$ ), relative to a pre-response baseline of -200 to $-100 \mathrm{~ms}$. The mean amplitude of the ERN was computed on incorrect response trials in a window from 0 to 50 ms following the response. The CRN consisted of the same measure computed on correct 
response trials. Consistent with previous studies, the $\triangle \mathrm{ERN}$ was also evaluated, and was calculated by subtracting the $\mathrm{CRN}$ from the ERN waveforms. The Pe was computed on incorrect and correct response trials in a window from 200 to $500 \mathrm{~ms}$.

\subsubsection{Attentional Control}

Pair Cancellation, a task drawn from the Woodcock-Johnson III (WJ-III) Tests of Cognitive Abilities (Woodcock \& Mather, 2000), was used to assess children's attentional control. In this task, children are presented with a worksheet with small pictures of dogs, balls, and cups. Children are asked to circle all of the ball-dog pairs in which a dog is presented after a ball, and are given 3 minutes to complete identify as many pairs as they can on the page. W-

scores are generated based on the number of correct pairs children find within 3 minutes.

\section{Results}

In this section, children's behavioral and ERP data from each time point are first evaluated on average. Because of the repeated-measures structure of the data, a GreenhouseGeisser correction was employed in analyses where appropriate. Following a description of behavior and error-related ERPs as assessed in the fall and the spring, changes in these measures over time are outlined. Next, relations between performance on the Zoo Task and standardized measures of response inhibition gathered from the Woodcock Johnson are described. To accomplish this analytic goal, ERN and Pe amplitudes were further compared through the use of t-tests, and differences in children's performance across the school year were explored by examining change scores, as well as through correlational and multiple regression analyses. For all correlational analyses, to minimize the risk of Type 1 errors, we employ the BenjaminiHochberg procedure to control the false discovery rate (Benjamini \& Hochberg, 1995). Put another way, using this approach the aim is to reduce the risk of reporting significant associations that are actually false positives. Here we report only associations significant at a false discovery rate of .05. Finally, data drawn from a comparison sample of children are examined to describe 
ERN AND EF 15

the impact of repeated assessments on children's behavioral and ERP data and to distinguish practice or strategy changes from true developmental changes.

\subsection{Change across the Academic Year: Average Performance from Fall to Spring in the}

\section{Longitudinal Sample}

\subsubsection{Go/No-go Task: Behavior}

Accuracy and RT data on error and correct trials in the fall and spring can be seen in

Table 1. In the fall, in the beginning of the school year, the mean percentage of errors of commission per subject contributing to the analysis was $31.30 \%$ of the No-Go trials. In contrast, children accurately responded on $91.02 \%$ Go trials. Accuracy on No-Go trials decreased on average slightly in the spring $(t(1,44)=-1.87, p=.07)$, with children erring on $35.06 \%$ of No-Go Trials; however, they were also correct on Go trials with significantly greater frequency $(t(1,44)$ $=-3.28, p<.01)$. Some degree of consistency was observed in children's accuracy over time, with percentage of errors $(r=.49, p<.01)$ on No-go trials correlated between time 1 and time 2 . Similarly, correct $(r=.48, \mathrm{p}<.01)$ responses on Go trials were correlated across time points. Children also became increasingly fast in responding from fall to spring on both error $(t$ $(1,44)=6.33, p<.01)$ and correct trials $(t(1,44)=8.49, p<.01)$. Associations between RT in the fall and spring were relatively high on for both error $(r=.67, p<.01)$ and correct trials $(r=.70, p$ $<.01)$.

- INSERT TABLE 1 ABOUT HERE -

\subsubsection{Go/No-go Task: The ERN, CRN, and Pe}

Response-locked waveforms from the Go/No-Go task at electrode sites along the midline at $\mathrm{FCz}, \mathrm{Cz}$, and $\mathrm{Pz}$ from fall and spring can be seen in Figure 1. Visual inspection of these waveforms reveals an ERN-like negative deflection around the time of error commission relative to correct responses at both frontal sites along the midline, $\mathrm{FCz}$ and $\mathrm{Cz}$. Average amplitudes on error and correct trials can be seen in Table 2. The presence of the ERN at both timepoints was further assessed using a three (Site: $\mathrm{FCz}, \mathrm{Cz}$, and $\mathrm{Pz}$ ) x two (Trial Accuracy) $\mathrm{x}$ two (Time point) 
repeated-measures ANOVA. Revealing the presence of the ERN at each timepoint, analyses revealed a main effect of site $(F(2,84)=14.54, p<.01$, partial $\eta 2=0.26)$ and trial type $(F(1$, $42)=23.64, p<.01$, partial $\eta 2=0.36$ ). Moreover, there was a significant interaction between Site and Trial Type $(F(2,88)=17.82, p<.01$, partial $\eta 2=0.30)$, revealing differences in amplitude between error trials (ERN) and correct trials (CRN) as a function of electrode site, with greater negativity at frontal relative to posterior sites on error trials in the fall and the spring.

However, main effect of time was not observed $(F(1,42)=1.03, p=.32$, partial $\eta 2=0.02)$. A significant site $\mathrm{x}$ time $(F(2,84)=2.09, p=.09$, partial $\eta 2=0.05)$ and trial $\mathrm{x}$ time interaction $(F$ $(2,88)=1.03, p=.15$, partial $\eta 2=0.02)$ were not observed. In addition, the overall interaction between site, trial type, and time was not significant $(F(2,84)=2.70, p=.06$, partial $\eta 2=0.02)$.

\section{- INSERT FIGURE 1 ABOUT HERE -}

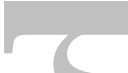

- INSERT TABLE 2 ABOUT HERE -

As can be seen in the two far right panels in Figure 1, the Pe was also observed at $\mathrm{Pz}$ in the fall and the spring, as demonstrated using a three (Site: FCz, Cz, and Pz) x two (Trial Accuracy) $\mathrm{x}$ two (Time point) repeated-measures ANOVA, where the trial $\mathrm{x}$ site interaction was significant $(F(2,84)=122.01, p<.01$, partial $\eta 2=0.73)$. However, this pattern did not vary as a function of time point $(F(2,88)=0.11, p=.85$, partial $\eta 2=0.00)$. As with the ERN and CRN, the Pe on error trials was correlated from fall to spring $(r=.49, p<.01)$, and the corresponding positivity on correct trials was also correlated from fall to spring $(r=.61, p<.01)$.

\subsubsection{Attention Control}

When considering children's performance on the standardized Attention Control measure on the WJ-III, on average children scored $461.42(S D=10.92)$ on the fall and $466.16(S D=9.58)$ in the spring. This increase in performance was significant, with greater scores observed at the end of the academic year $(t(1,44)=-3.21, p<.01)$. Fall and spring scores were also correlated $(r$ $=.48, p<.01)$. 


\subsection{Associations Behavioral Measures of EF and ERPs on the Go/No-go task at Each Time}

\section{Point}

Associations between behavioral EF measures at each time point can be found in Table

3. As can be seen in the top panel, evidence was observed for moderate associations in the fall between different EF component skills as assessed via accuracy and error RT on the Go/No-go task and W-scores on the WJ measure of Attention Control. A similar pattern was observed in the spring, although the correlations appear larger between RT and attention control. Thus, the evidence suggests that measures from the behavioral assessments of EF show associations with performance in the Go/No-go task.

- INSERT TABLE 3 ABOUT HERE -

The ERP measures can also be examined to determine whether they show associations with performance in the Go/No-go task as well as the behavioral EF measures. When considering relations between ERP measures drawn from the Go/No-go task and behavior indices from the same task in the fall (see Table 4), no relations between ERP measures and the behavioral measures of component EF skills were observed.

In contrast, in the spring, (lower panel of Table 4), the ERN was associated with error RT within the Go/No-Go task: larger (more negative) ERNs were associated with slower RTs ( $r=$ $.44, p<.01)$. No other associations between behavior and ERP measures on the task were observed. Moreover, there was no evidence for concurrent relations between the ERN, CRN, or Pe and EF skill of attention control was identified (see Table 4).

- INSERT TABLE 4 ABOUT HERE -

\subsection{Relating Error Monitoring to Changes in EF Behavior over Time}

\subsubsection{Relations between Individual Differences in Error Monitoring and EF Behavior in the}

\section{Fall with Changes in EF Behavior across the School Year}

Although our evidence for concurrent links between EF behavior and ERP correlates of error monitoring was modest, of equal importance is the extent to which individual differences in 
error monitoring or EF skills in the fall predict changes in brain or behavior across the academic year. To address this question, we performed a series of regressions examining the extent to which children's fall ERP amplitudes predicted growth in behavioral measures of response inhibition and attention control.

We explored the possibility that children's initial error monitoring responses, as indexed by the ERN and the Pe, might predict changes in children's response inhibition and attentional skills over time. To test these associations, we examined the extent to which children's fall ERN scores predicted spring EF behavior, accounting for the same EF behavior in the fall and children's age. As can be seen in Table 5, across all EF outcomes, fall EF scores predicted later performance in the spring. These analyses also revealed that larger (more negative) ERNs at $\mathrm{Cz}$, as assessed in the fall predicted greater attention control $(\beta=-.44, p<.05)$ at the end of the school year $\left(F(3,41)=12.47, p<.01, R^{2}=.48\right)$. No other significant associations were observed between fall ERN or CRN amplitudes and spring scores, within the Go/No-go task. Moreover, when considering the role that the Pe might play in changes in behavior across the school year in these analyses, it was clear that the Pe was not predictive of later cognitive control.

- INSERT TABLE 5 ABOUT HERE -

\subsubsection{Associations between Changes in EF Behavior and Error Monitoring from Fall to}

\section{Spring}

A final set of analyses test more directly the association between changes in neural activity and changes in EF behavior. Specifically, we were interested in exploring the extent to which changes in cognitive control as measured using neural measures might be related to behavioral changes observed in related EF skills. To examine this question, difference scores were first computed to obtain a value that reflects the changes in children's performance from the fall to spring time point for both ERP and behavioral measures. Following this, correlations between these change scores were computed. 
The full pattern of associations can be seen in Table 6. Figure 2 shows scatterplots illustrating the significant relationships between error-related ERPs and behavior in the Go/No task. As is portrayed in Figure 2, changes in the ERN from the fall to the spring are associated with changes in measures of Attention Control $\mathrm{Cz}(r=.47, \mathrm{p}<.01)$. Increasing negativity in the ERN from fall to spring was associated with greater growth in attention control.

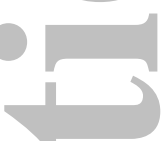

- INSERT TABLE 6 ABOUT HERE - INSERT FIGURE 2 ABOUT HERE -

\subsubsection{Elucidating Changes in Behavior over Time: A Comparison Sample}

One puzzling pattern of results observed here was the change in behavioral performance
in the Go/No-go task from fall to spring: overall children became faster over time, while accuracy increased on Go trials and decreased on No-go trials (see Table 1). To better understand this trend, we examined data drawn from a cohort of children tested only once on the Go/No-Go measure. As noted above, testing context and age of these children were matched with that of their peers who participated in the longitudinal investigation, making it possible for us to compare two groups of children varying only in prior experience playing the Go/No-Go game.

For each measure we compared the spring values for the two groups. Differences in measures of RT as a function of the number of times children engaged in the task were observed, with children who had completed the task twice responding significantly faster on both error $(t=$ $-2.30, p=.02)$ and correct trials $(t=-2.06, p=.04)$. The two groups did not differ significantly in accuracy on Go or No-go trials, although the mean No-go accuracy for the group tested in the spring fell numerically between the fall and spring values for the group tested twice. Thus, although we cannot rule out a speed-accuracy tradeoff underlying the change from fall to spring in the group tested twice, the comparable RTs for the two groups assessed in the spring suggests that some of the speeding represents a true developmental change, rather than a practice or familiarity effect from the fall testing.

\section{Discussion}

Psychophysiology

This article is protected by copyright. All rights reserved. 


\subsection{Considering Change over Time in EF and Error Monitoring}

In this investigation, longitudinal changes in ERP correlates of error monitoring and behavioral measures of Response Inhibition and Attention Control were assessed in Kindergarten and First Grade Children across one academic year. Considering the ERPs associated with error monitoring, results indicated that ERN and the Pe amplitudes were moderately correlated over time. Further analyses revealed that individual differences in the ERN at the start of the school year were associated with changes in attentional control from fall to spring. Finally, changes in ERN amplitude from fall to spring were related to changes in EF behaviors over that interval. Specifically, increases in attention control across the year were associated with the ERN becoming larger (more negative).

\subsubsection{Development of the ERN and Pe?}

Although there are few reports of repeated measures of children's ERN and Pe, and no reports of these associations in this particular age range across this developmental window using the same measures over time, the data presented here reveal stronger associations between the ERN and Pe over time than reported in previous studies (DuPuis et al., 2015). Still, the degree of correlation across repeated assessments in this sample is relatively low compared to analogous findings in adults. Indeed, similar studies conducted with adults reveal associations between repeated assessments of the ERN that are much stronger, suggesting that error monitoring is more stable in adulthood relative to early childhood (Olvet \& Hajcak, 2009; Segalowitz et al., 2010; Weinberg \& Hajcak, 2011).

changes in ERP indices across the 6-month window. This is not entirely surprising given the protracted neural development in regions of the brain associated with error monitoring (Sowell et al., 1999) and is consistent data indicating that age is not a strong predictor of the ERN in early childhood (Grammer et al., 2014). Although amplitude of the ERN on error trials is often of greatest interest to researchers focused on cognitive control, in these data the greatest 
amount of difference over time appears in the amplitude observed on CRN, or correct trials. This finding suggests that focusing on children's responses to successful trials might provide important information regarding changes in error monitoring during this developmental period.

In contrast, behavioral data drawn from the same Go/No-go task from which the ERP data were elicited portray a different pattern of development, with changes observed in children's accuracy and RT. Specifically, children's rate of erring increased slightly from fall to spring, while at the same time significant increases in speed were observed. Such a pattern suggests that the children might have been trading accuracy for speed with increased practice on the task. We hypothesized that strategic changes in performance that also might be impacting the ERP

responses. It is worth noting that this set of questions highlights the importance of longitudinal data - indeed, with cross-sectional data this pattern of results would have gone undetected.

By comparing behavioral data of children who had experience the Go/No-go measure once vs. twice, it was possible to examine this question. Indeed, children of the same age assessed only one time with the task showed significantly different patterns of behavior. These results support the hypothesis that upon being tested a second time, children either strategically changed their behavioral approach (although perhaps not for the better) or else showed some other practice or familiarity effect stemming from their earlier experience with the task. These types of behavioral adjustments might be less frequently observed in adult participants, for whom responding in a basic Go/No-go task may be easier and more automatized.

\subsubsection{Linking Error Monitoring and EF Development}

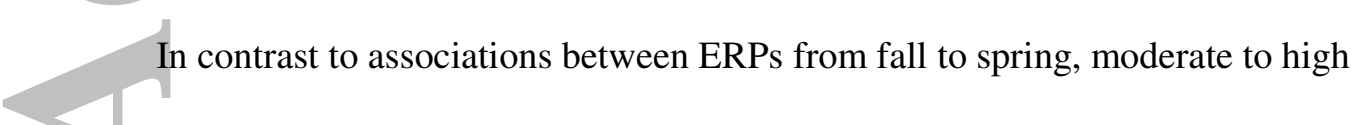
associations in attention control were observed over time, with significant increases in both of these skills observed from fall to spring. Examining ERPs associated with error monitoring contributes to our understanding of how these changes might be occurring. Specifically, individual differences in error monitoring in the fall were associated with changes in attention 
control across the school year. Moreover, changes in the amplitude of the ERN across this same period were also associated with changes in attention control.

To our knowledge, despite the assumption that the ERN, CRN, and Pe reflect neural processes associated with cognitive control, and that such control processes are important outside the laboratory, these are the first data linking these ERP components to a broader complement of behaviors in young children. Although it is not possible to say what is driving the changes observed in either error monitoring or in behavior, these results do indicate that the neural systems underlying error monitoring processes have implications for the behavioral changes in cognitive control observed in early childhood. Children's immediate neural responses to error commission could reflect their ability to detect instances where cognitive control is needed, which, in turn, could drive the observed changes in response inhibition and attention control. These data also clearly reveal that that examining ERPs does not provide the same information about cognitive control as behavioral measures or vise versa, suggesting that each level of measurement is providing shared and unique information regarding the development of cognitive control processes.

\subsubsection{Limitations and Future Directions}

The data also highlight the important gaps in knowledge facing theories of cognitive control: how measures of neural activity and behavior in simple laboratory tasks can shed light on the real-world scenarios in which cognitive control is important. Although these results provide insight into developmental changes across an important window of time, a third time point of data would be necessary to examine trajectories of growth at each level of analysis. In addition, as issues of measurement have been prevalent in research on children's cognitive development (Morrison \& Grammer, 2012), future investigations should include additional measures of these skills in young children. In particular, it would be informative to know the extent to which error monitoring ERPs are associated with cognitive control processes children use at school or at home. 
Finally, although changes were observed in both brain and behavior, these data provide little insight into the factors that might be driving this change. It is possible that age-related maturation alone promotes changes in the neural correlates in error monitoring, but it is also likely these changes can be attributed to experiences that children have at home or in school.

Future work should examine the impact of contextual factors in the development of brain and behavioral correlates of cognitive control. We suggest that computational models, especially those seeking to model processes applicable in broader, real-world circumstances, would do well to consider constraints based on the developmental trajectories of cognitive control processes as well as the contextual drivers of developmental change.

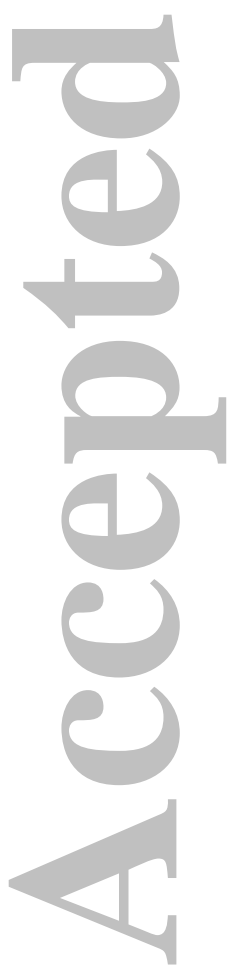


ERN AND EF 24

References

Alexander, W. H., \& Brown, J. W. (2010). Computational models of performance monitoring and cognitive control. Topics in cognitive science, 2(4), 658-677. https:// doi: 10.1111/j.17568765.2010.01085.x

Anderson, P. (2002). Assessment and Development of Executive Function (EF) During Childhood. Child Neuropsychology, 8(2), 71-82.

r https://doi.org/10.1076/chin.8.2.71.8724

Benjamini, Y., and Y. Hochberg. 1995. Controlling the false discovery rate: a practical and powerful approach to multiple testing. Journal of the Royal Statistical Society B 57: 289-300.

Blair, C. (2002). School readiness: Integrating cognition and emotion in a neurobiological conceptualization of children's functioning at school entry. American Psychologist, 57(2), 111-127. https://doi.org/10.1037/0003-066X.57.2.111

Botvinick, M. M., Braver, T. S., Barch, D. M., Carter, C. S., \& Cohen, J. D. (2001). Conflict monitoring and cognitive control. Psychological Review, 108(3), 624-652. https://doi.org/10.1037/0033-295X.108.3.624

Chiew, K., \& Braver, T. S. (2017). Context processing and control in the human brain: from gating models to dual mechanisms. In T. Egner (Ed.), The Wiley Handbook of Cognitive Control. Chichester, West Sussex: John Wiley \& Sons.

Clawson, A., Clayson, P. E., Keith, C. M., Catron, C., \& Larson, M. J. (2017). Conflict and performance monitoring throughout the lifespan: An event-related potential (ERP) and temporospatial component analysis. Biological Psychology, 124, 87-99. https://doi.org/10.1016/j.biopsycho.2017.01.012

Coles, M. G., Scheffers, M. K., \& Holroyd, C. B. (2001). Why is there an ERN/Ne on correct trials? Response representations, stimulus-related components, and the theory of error- 
ERN AND EF 25

processing. Biological psychology, 56(3), 173-189. https://doi.org/10.1016/S03010511(01)00076-X

Davies, P. L., Segalowitz, S. J., \& Gavin, W. J. (2004). Development of response-monitoring ERPs in 7-to 25-year-olds. Developmental Neuropsychology, 25(3), 355-376. http://dx.doi.org/10.1207/s15326942dn2503_6

Downes, M., Bathelt, J., \& De Haan, M. (2017). Event-related potential measures of executive

functioning from preschool to adolescence. Developmental Medicine \& Child Neurology, n/a-n/a. https://doi.org/10.1111/dmcn.13395

Duckworth, A. L., \& Seligman, M. P. E. (2006). Self-discipline gives girls the edge: Gender in self-discipline, grades, and achievement test scores. Journal of Educational Psychology, 98(1), 198-208. https://doi.org/10.1037/0022-0663.98.1.198

DuPuis, D., Ram, N., Willner, C. J., Karalunas, S., Segalowitz, S. J., \& Gatzke-Kopp, L. M. (2015). Implications of ongoing neural development for the measurement of the errorrelated negativity in childhood. Developmental Science, 18(3), 452-468. 1 https://doi.org/10.1111/desc.12229

Eslinger, P. J. (1996). Conceptualizing, describing, and measuring components of executive function: A summary. In G. R. Lyon \& N. A. Krasnegor (Eds.), Attention, memory, and executive function (pp. 367-395). Baltimore, MD: Paul H Brookes Publishing.

Falkenstein, M. (2004). ERP correlates of erroneous performance. In Errors, conflicts, and the brain. Current opinions on performance monitoring (Vol. 1, pp. 5-14). Max-PlanckInstitut für Kognitions-und Neurowissenschaften Leipzig.

Falkenstein, M., Hohnsbein, J., Hoormann, J., \& Blanke, L. (1991). Effects of crossmodal divided attention on late ERP components. II. Error processing in choice reaction tasks. Electroencephalography and Clinical Neurophysiology, 78(6), 447-455. https://doi.org/10.1016/0013-4694(91)90062-9 
Gehring, W. J., Goss, B., Coles, M. G. H., Meyer, D. E., \& Donchin, E. (1993). A neural system for error detection and compensation. Psychological Science, 4(6), 385-390. https://doi.org/10.1111/j.1467-9280.1993.tb00586.x

Gehring, W. J., Liu, Y., Orr, J. M., \& Carp, J. (2012). The error-related negativity (ERN/Ne). Oxford Handbook of Event-Related Potential Components, 231-291.

Grammer, J. K., Carrasco, M., Gehring, W. J., \& Morrison, F. J. (2014). Age-related changes in I error processing in young children: A school-based investigation. Developmental Cognitive Neuroscience, 9, 93-105. https://doi.org/10.1016/j.den.2014.02.001

Grammer, J. K., Coffman, J. L., Ornstein, P. A., \& Morrison, F. J. (2013). Change over Time: Conducting Longitudinal Studies of Children's Cognitive Development. Journal of Cognition and Development, 14(4), 515-528. http://dx.doi.org/10.1080/15248372.2013.833925

Hogan, A. M., Vargha-Khadem, F., Kirkham, F. J., \& Baldeweg, T. (2005). Maturation of action monitoring from adolescence to adulthood: an ERP study. Developmental Science, 8(6), 525-534. https://doi.org/10.1111/j.1467-7687.2005.00444.x

Holroyd, C. B., \& Coles, M. G. (2002). The neural basis of human error processing: reinforcement learning, dopamine, and the error-related negativity. Psychological review, 109(4), 679. http://dx.doi.org/10.1037/0033-295X.109.4.679

Hughes, C., Ensor, R., Wilson, A., \& Graham, A. (2009). Tracking executive function across the transition to school: A latent variable approach. Developmental Neuropsychology, 35(1), 20-36. https://doi.org/10.1080/87565640903325691

Kim, M.H., Grammer, J. K., Marulis, L. M., Carrasco, M., Morrison, F. J., \& Gehring, W. J. (2016). Early math and reading achievement are associated with the error positivity. Developmental Cognitive Neuroscience, 22, 18-26. https://doi.org/10.1016/j.den.2016.09.002 
ERN AND EF 27

Kim, M. H., Marulis, L. M., Grammer, J. K., Morrison, F. J., \& Gehring, W. J. (2017).

Motivational processes from expectancy-value theory are associated with variability in the error positivity in young children. Journal of Experimental Child Psychology, 155, 32-47. https://doi.org/10.1016/j.jecp.2016.10.010

Klein, C. (2003). Assessing the development of executive functions. International Society for the Study of Behavioural Development Newsletter, 43(1), 8-11.

Ladouceur, C. D., Dahl, R. E., Birmaher, B., Axelson, D. A., \& Ryan, N. D. (2006). Increased error-related negativity (ERN) in childhood anxiety disorders: ERP and source localization. Blackwell Publishing, 47(10), 1073-1082. https://doi.org/10.1111/j.14697610.2006.01654.x

Lan, X. (2009). Bridging Naturalistic and Laboratory Measures of Self-Regulation: The Development and Validation of Challenge Tasks. Retrieved from http://deepblue.lib.umich.edu/handle/2027.42/63771

Lehto, J. E., Juujärvi, P., Kooistra, L., \& Pulkkinen, L. (2003). Dimensions of executive functioning: Evidence from children. British Journal of Developmental Psychology, 21(1), 59-80. https://doi.org/10.1348/026151003321164627

Lerner, M. D., \& Lonigan, C. J. (2014). Executive function among preschool children: Unitary versus distinct abilities. Journal of psychopathology and behavioral assessment, 36(4), 626-639. https://doi.org/10.1007/s10862-014-9424-3

Luciana, M. (2003). Practitioner Review: Computerized assessment of neuropsychological function in children: clinical and research applications of the Cambridge Neuropsychological Testing Automated Battery (CANTAB). Journal of Child Psychology and Psychiatry, 44(5), 649-663. https://doi.org/10.1111/1469-7610.00152

McAuley, T., \& White, D. A. (2011). A latent variables examination of processing speed, response inhibition, and working memory during typical development. Journal of 
Experimental Child Psychology, 108(3), 453-468.

https://doi.org/10.1016/j.jecp.2010.08.009

Meyer, A., Bress, J. N., \& Proudfit, G. H. (2014). Psychometric properties of the error-related negativity in children and adolescents. Psychophysiology, 51(7), 602-610. https://doi.org/ 10.1111/psyp. 12208

Miyake, A., \& Friedman, N. P. (2012). The nature and organization of individual differences in

executive functions: Four general conclusions. Current Directions in Psychological Science, 21(1), 8-14. https://doi.org/10.1177/0963721411429458

Miyake, A., Friedman, N. P., Emerson, M. J., Witzki, A. H., Howerter, A., \& Wager, T. D. (2000). The Unity and Diversity of Executive Functions and Their Contributions to Complex "Frontal Lobe" Tasks: A Latent Variable Analysis. Cognitive Psychology, 4l(1), 49-100. https://doi.org/10.1006/cogp.1999.0734

Morrison, F. J., \& Grammer, J. K. (2012). Conceptual clutter and measurement mayhem: proposals for cross disciplinary integration in conceptualizing and measuring executive function. In J. A. Griffin \& P. McCardle (Eds.), Executive function in preschool age children: Integrating measurement, neurodevelopment, and translational research. American Psychological Association (APA) Press.

Olvet, D. M., \& Hajcak, G. (2009). Reliability of error-related brain activity. Brain Research, 1284, 89-99. https://doi.org/10.1016/j.brainres.2009.05.079

Richardson, C., Anderson, M., Reid, C. L., \& Fox, A. M. (2011). Neural indicators of error processing and intraindividual variability in reaction time in 7 and 9 year-olds.

Developmental Psychobiology, 53(3), 256-265. https://doi.org/10.1002/dev.20518

Santesso, D. L., \& Segalowitz, S. J. (2008). Developmental differences in error-related ERPs in middle- to late-adolescent males. Developmental Psychology, 44(1), 205-217. https://doi.org/10.1037/0012-1649.44.1.205 
ERN AND EF 29

Santesso, D. L., Segalowitz, S. J., \& Schmidt, L. A. (2006). Error-related electrocortical responses in 10-year-old children and young adults. Developmental Science, 9(5), 473481. https://doi.org/10.1111/j.1467-7687.2006.00514.x

Schneider, W., Schlagmüller, M., \& Visé, M. (1998). The impact of metamemory and domainspecific knowledge on memory performance. European Journal of Psychology of Education, 13(1), 91-103. https://doi.org/10.1007/BF03172815

Segalowitz, S. J., Santesso, D. L., Murphy, T. I., Homan, D., Chantziantoniou, D. K., \& Khan, S. (2010). Retest reliability of medial frontal negativities during performance monitoring. Psychophysiology, 47(2), 260-270. https://doi.org/10.1111/j.1469-8986.2009.00942.x

Shonkoff, J., \& Phillips, D. (Eds.). (2000). From neurons to neighborhoods: The science of early childhood development. Washington, DC: National Academies Press.

Sowell, E. R., Thompson, P. M., Holmes, C. J., Batth, R., Jernigan, T. L., \& Toga, A. W. (1999). Localizing Age-Related Changes in Brain Structure between Childhood and Adolescence Using Statistical Parametric Mapping. NeuroImage, 9(6), 587-597. https://doi.org/10.1006/nimg.1999.0436

Tamnes, C. K., Walhovd, K. B., Torstveit, M., Sells, V. T., \& Fjell, A. M. (2013). Performance monitoring in children and adolescents: A review of developmental changes in the errorrelated negativity and brain maturation. Developmental Cognitive Neuroscience, 6(0), 113. https://doi.org/10.1016/j.den.2013.05.001

Torpey, D. C., Hajcak, G., Kim, J., Kujawa, A., \& Klein, D. N. (2012). Electrocortical and behavioral measures of response monitoring in young children during a Go/No-Go task. Developmental Psychobiology, 54(2), 139-150. https://doi.org/10.1002/dev.20590

Weinberg, A., \& Hajcak, G. (2011). Longer term test-retest reliability of error-related brain activity: Long-term reliability of the ERN. Psychophysiology, 48(10), 1420-1425. https://doi.org/10.1111/j.1469-8986.2011.01206.x

Psychophysiology

This article is protected by copyright. All rights reserved. 
Welsh, M. C. (2001). The prefrontal cortex and the development of executive functions. In A. F. Kalverboer \& A. Gramsbergen (Eds.), Handbook of brain and behaviour in human development (pp. 767-789). Dordrecht, Netherlands: Kluwer.

Welsh, M. C., Pennington, B. F., \& Groisser, D. B. (1991). A normative-developmental study of executive function: A window on prefrontal function in children. Developmental Neuropsychology, 7(2), 131-149. https://doi.org/10.1080/87565649109540483

Wiebe, S. A., Sheffield, T., Nelson, J. M., Clark, C. A. C., Chevalier, N., \& Espy, K. A. (2011). The structure of executive function in 3-year-olds. Journal of Experimental Child Psychology, 108(3), 436-452. https://doi.org/10.1016/j.jecp.2010.08.008

Wiersema, J. R., van der Meere, J. J., \& Roeyers, H. (2007). Developmental changes in error monitoring: An event-related potential study. Neuropsychologia, 45(8), 1649-1657. https://doi.org/10.1016/j.neuropsychologia.2007.01.004

Willoughby, M. T., Blair, C. B., Wirth, R. J., \& Greenberg, M. (2010). The measurement of executive function at age 3 years: Psychometric properties and criterion validity of a new (1) battery of tasks. Psychological assessment, 22(2), 306. http://dx.doi.org/10.1037/a0018708

Yeung, N., \& Sanfey, A. G. (2004). Independent coding of reward magnitude and valence in the human brain. Journal of Neuroscience, 24(28), 6258-6264. https://doi.org/10.1523/JNEUROSCI.4537-03.2004

Zelazo, P. D., Craik, F. I. M., \& Booth, L. (2004a). Executive function across the life span. Acta Psychologica, 115(2-3), 167-183. https://doi.org/10.1016/j.actpsy.2003.12.005

Zelazo, P. D., \& Frye, D. (1998). Cognitive complexity and control: II. The development of executive function in childhood. Current Directions in Psychological Science, 7(4), 121126. 


\section{AUTHORS' NOTE}

This research was supported by a grant from the National Institutes of Health (R21 HD059085). We appreciate the support of the participating schools staff, families, and students who participated in this project. In addition, we wish to thank Kristall Kneiper, Palak Vani, Alexander Daguanno, Kasia Garner, Shella Marder, Kaille Meguiar, Mahya Rahimian, and Anna Shu for their assistance with task development and testing, data collection, and coding. We are grateful to Jennifer McDermott and colleagues for sharing software and the design of the Go/No-go task. Requests for reprints should be sent to Jennie K. Grammer, email: grammer@ucla.edu.

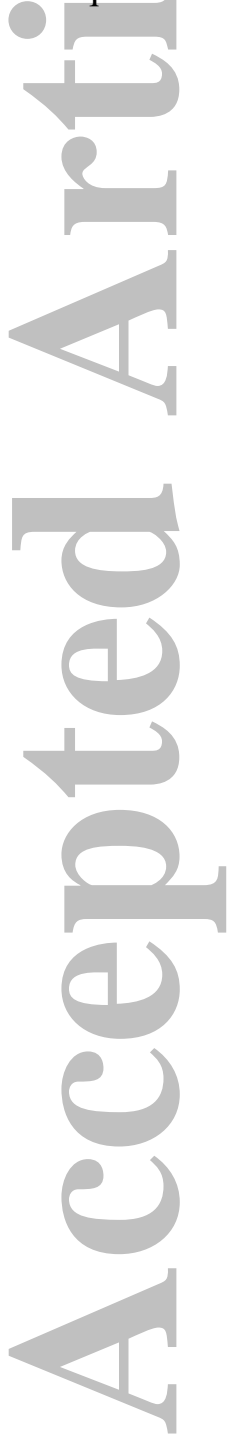


Table 1

Behavioral Performance on Error and Correct Trials in the Go/No-Go Task

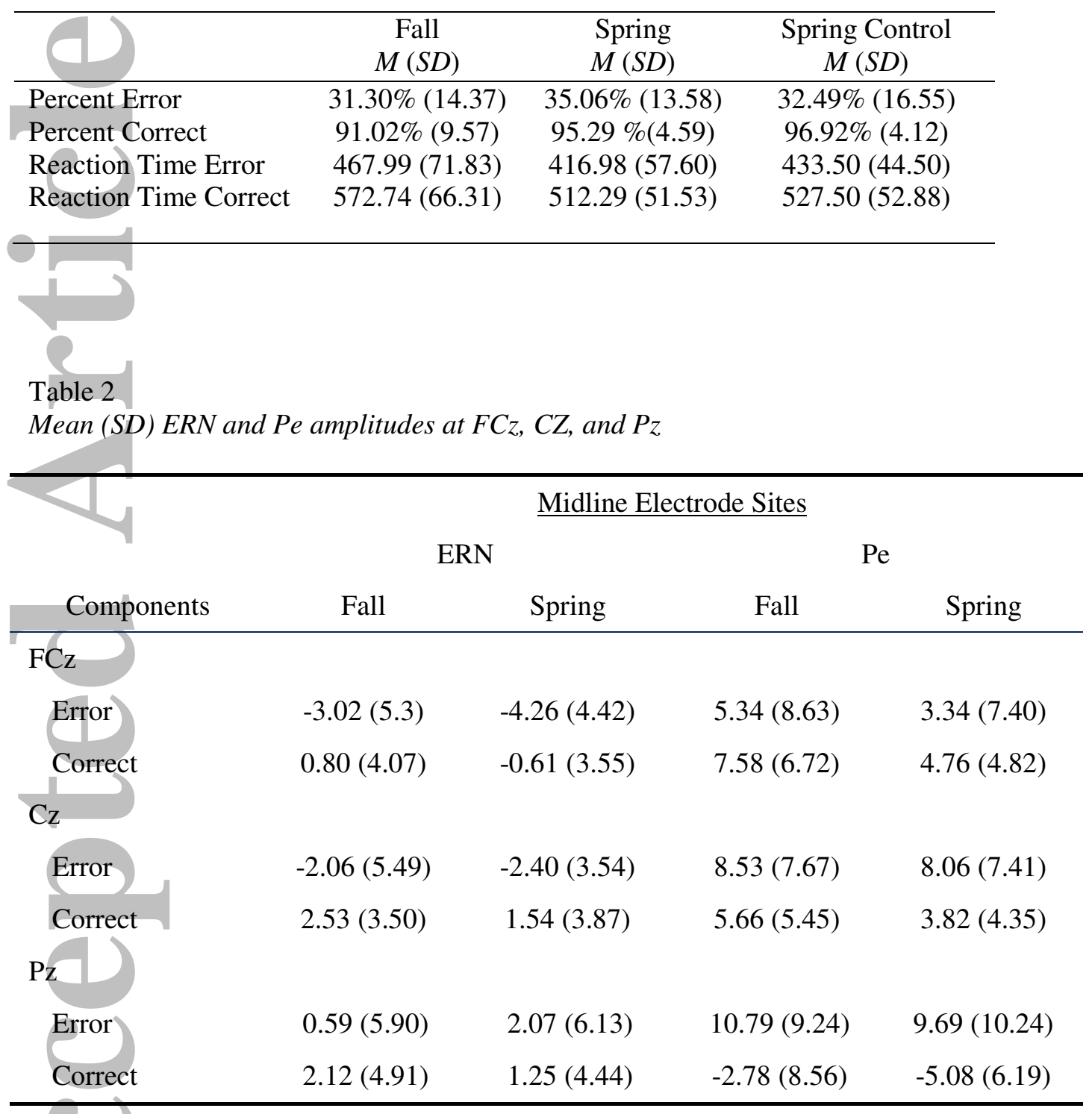

Psychophysiology

This article is protected by copyright. All rights reserved. 
ERN AND EF 33

Table 3

Associations between Behavioral Measures of EF in the Fall (top panel) and Spring (bottom panel)

\begin{tabular}{lllll} 
Response Inhibition & $\%$ Error & \% Correct & RT Error & RT Correct \\
\hline \% Correct & .177 & & & \\
RT Error & -.322 & $-.394^{*}$ & & \\
RT Correct & $-.586^{*}$ & $-.498^{*}$ & $.809^{*}$ & \\
\hline Attention Control & -.104 & $.379^{*}$ & $-.393^{*}$ & -.301 \\
\hline
\end{tabular}

Spring

\begin{tabular}{lllll} 
Response Inhibition & $\%$ Error & \% Correct & RT Error & RT Correct \\
\hline$\%$ Correct & -.089 & & & \\
RT Error & -.234 & $-.363^{*}$ & & \\
RT Correct & $-.389^{*}$ & $-.418^{*}$ & $.729^{*}$ & \\
\hline Attention Control & -.250 & $.468^{*}$ & $-.425^{*}$ & $-.37^{*}$
\end{tabular}

Note. ${ }^{*}$ Correlations significant at a false discovery rate of .05 , as assessed using the BenjaminiHochberg procedure.

\section{Table 4}

Associations between the ERN, CRN, and Pe and Behavioral Measures of EF in the Fall (top panel) and Spring (bottom panel)

\begin{tabular}{llllll}
\hline Fall & \multicolumn{5}{c}{ Response Inhibition: Go/No-go } \\
& \multicolumn{7}{c}{ Attention Control } \\
\hline ERP Measures & $\%$ Error & \% Correct & RT Error & RT Correct & A \\
\hline ERN at Cz & -.08 & .02 & .15 & -.04 & .26 \\
CRN at Cz & -.31 & .25 & .02 & -.04 & .19 \\
Pe Error at Pz & -.10 & .06 & .09 & .01 & .10 \\
Pe Correct at Pz & .00 & -.30 & .15 & .11 & -.21 \\
\hline
\end{tabular}

\begin{tabular}{llllll}
\hline Spring & \multicolumn{5}{c}{ Response Inhibition: Go/No-go } \\
\cline { 3 - 6 } ERP Measures & $\%$ Error & \% Correct & RT Error & RT Correct & Attention Control \\
\hline ERN at Cz & -.17 & -.15 & $.44^{*}$ & .30 & .00 \\
$\mathrm{CRN}$ at Cz & -.19 & .30 & .05 & -.08 & .11 \\
Pe Error at Pz & -.22 & .14 & .05 & -.22 & .20 \\
Pe Correct at Pz & .05 & -.13 & -.15 & -.15 & .00 \\
\hline
\end{tabular}

Note. ${ }^{*}$ Correlations significant at a false discovery rate of .05, as assessed using the BenjaminiHochberg procedure. 
ERN AND EF 34

Table 5

Simultaneous Regression Results: Unstandardized Regression Coefficients, Standard Errors, and $R^{2}$ Values of Associations between EF Behavior in the Fall and Spring,

Children's Age, and Fall ERN and Pe Amplitudes

\begin{tabular}{|c|c|c|c|c|c|}
\hline & $\frac{\text { Fall ERN at } \mathrm{Cz}}{\mathrm{B}(S E)}$ & $\frac{\text { Fall Pe at Pz }}{\mathrm{B}(S E)}$ & $\frac{\text { Fall EF Skill }}{\mathrm{B}(S E)}$ & $\frac{\text { Age }}{\mathrm{B}(S E)}$ & $R^{2}$ \\
\hline \multicolumn{6}{|l|}{$\begin{array}{l}\text { Spring Response } \\
\text { Inhibition }\end{array}$} \\
\hline Percent Error & $.00(.35)$ & $.04(.83)$ & $.46(.13)^{* *}$ & $-.21(.26)$ & .26 \\
\hline Percent Correct & $.01(.11)$ & $.03(.07)$ & $.20(.07)^{* *}$ & $.17(.09)$ & .30 \\
\hline Reaction Time Error & $-.06(1.3)$ & $-.31(.75)$ & $.53(.11)^{* *}$ & $-.20(1.11)$ & .45 \\
\hline Reaction Time Correct & $-.75(1.12)$ & $-.58(.64)$ & $.57(.10)^{* *}$ & $.35(.95)$ & .50 \\
\hline Spring Attention Control & $-.44(0.22)^{*}$ & $.11(.13)$ & $.41(.12)^{* *}$ & $.51(.18)^{* *}$ & .47 \\
\hline
\end{tabular}

Note. ${ }^{*}$ Correlations significant at a false discovery rate of .05, as assessed using the BenjaminiHochberg procedure.

Table 6

Associations between the Changes in the ERN, CRN, and Pe and Changes in Behavioral Measures of EF from the Fall to Spring (Spring Measure - Fall Measure)

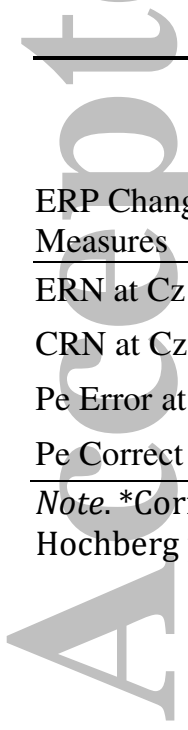

Response Inhibition: Go/No-go Change

ERP Change

\begin{tabular}{lllll} 
Measures & $\%$ Error $\quad \%$ Correct & RT Error & RT Correct & Attention Control \\
\hline ERN & &
\end{tabular}

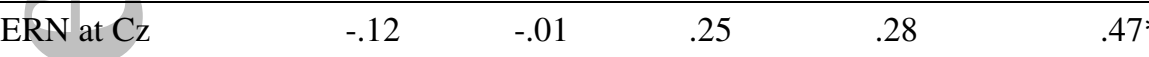

$\begin{array}{llllll}\mathrm{CRN} \text { at } \mathrm{Cz} & -.22 & .06 & .16 & .20 & -.05\end{array}$

$\begin{array}{llllll}\text { Pe Error at } \mathrm{Pz} & -.28 & -.12 & .22 & .17 & .06\end{array}$

$\begin{array}{llllll}\mathrm{Pe} \text { Correct at } \mathrm{Pz} & -.04 & -.31 & .10 & .03 & -.21\end{array}$

Note. *Correlations significant at a false discovery rate of .05, as assessed using the BenjaminiHochberg procedure. 
Figure 1. Response-locked error, correct, and difference waveforms at $\mathrm{FCz}, \mathrm{Cz}$, and $\mathrm{Pz}$ in the fall and spring.

Figure 2. Relations between Changes from Fall to Spring in ERN Amplitude at $\mathrm{Cz}$ and Attention Control. From fall to spring, a decrease in the ERN (less negativity) is associated with an increase in attention control.
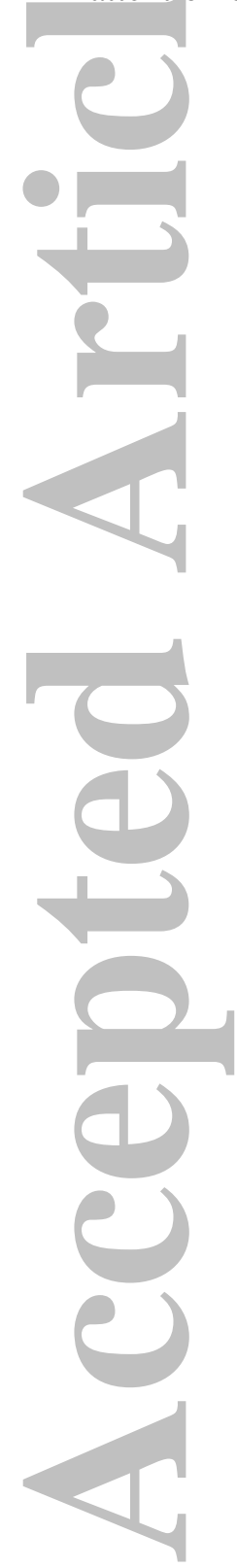


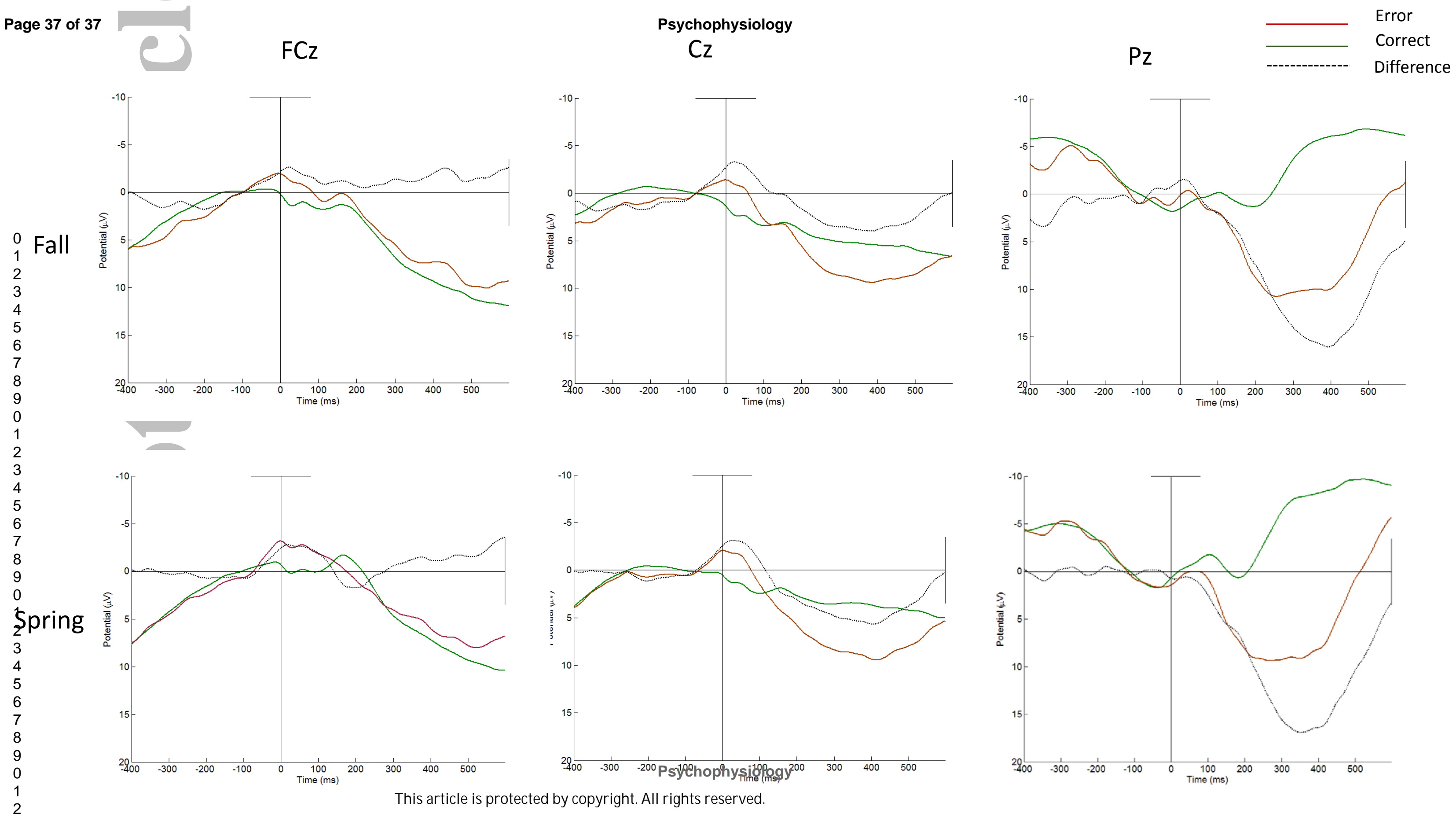




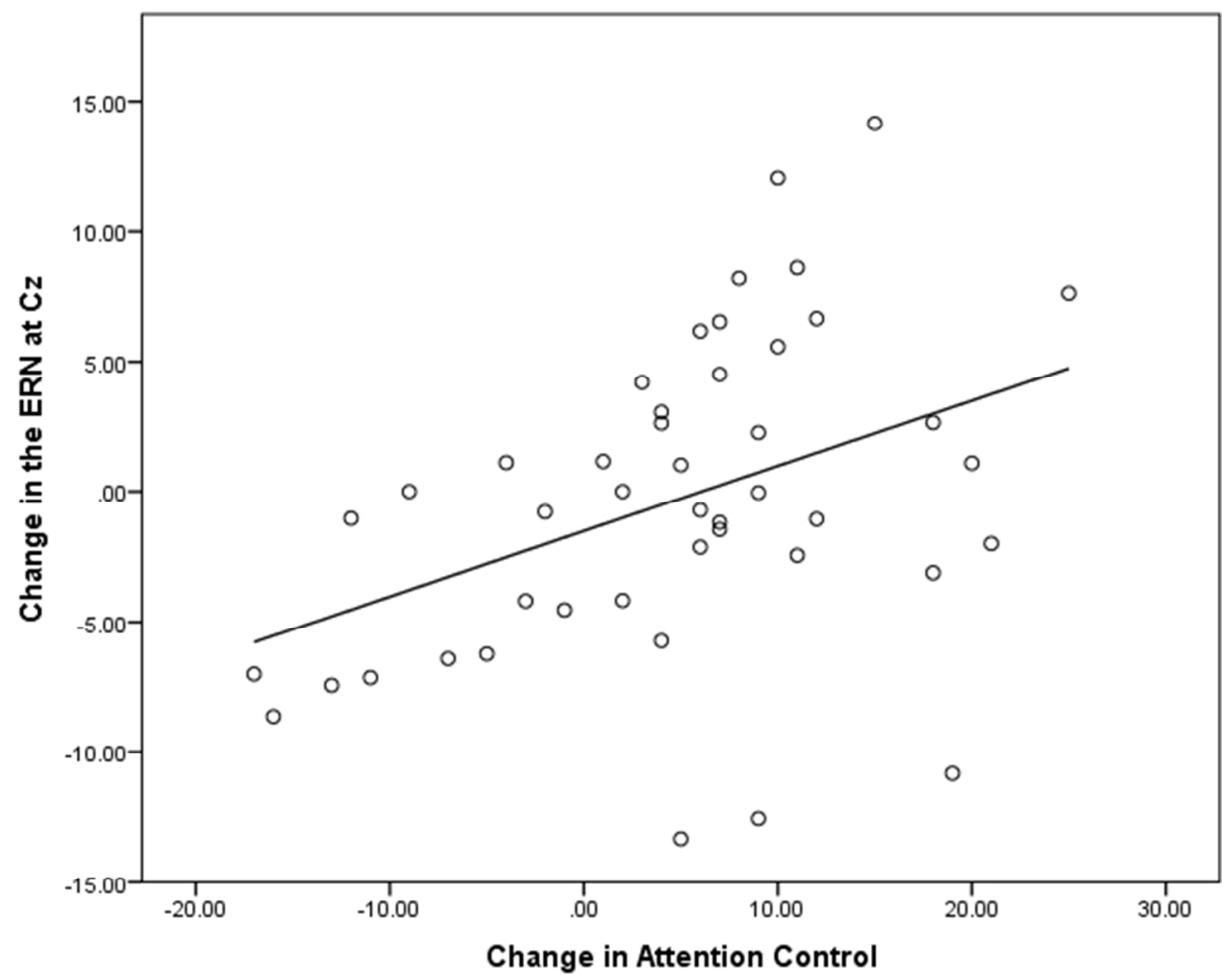

Figure 2. Relations between Changes from Fall to Spring in ERN Amplitude at $\mathrm{Cz}$ and Attention Control. From fall to spring, a decrease in the ERN (less negativity) is associated with an increase in attention control.

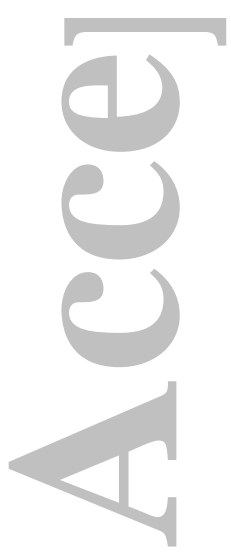

$166 \times 133 \mathrm{~mm}(96 \times 96 \mathrm{DPI})$ 